\title{
La ponderación de las valoraciones culturales en el error de prohibición
}

\author{
Alejandra Castillo Ara*
}

\begin{abstract}
RESUMEN
El artículo desarrolla el rol de las valoraciones culturales diferenciadas en el contexto del error de probibición, desde un punto de vista de la teoría de las normas, defendiendo la ponderación obligatoria de estas valoraciones por parte del juez al momento de la decisión judicial. Así también se propone una reformulación conceptual de lo que se entiende por visión de la antijuridicidad. Sobre esta base se propone la delimitación concreta de los presupuestos necesarios para afirmar conciencia de la antijuridicidad. Se sugiere la reformulación del estándar de conocimiento de la antijuridicidad, por una nomenclatura gradual que diferencia entre conocimiento, comprensión e internalización. Se introduce la idea de una defensa complementaria en materia de error de probibición culturalmente condicionado, afirmando la estrategia de defensa en el planteamiento de una defensa cultural, en tanto, la existencia de una cosmovisión valorativa diferenciada por parte de quien comete el delito.
\end{abstract}

Error de prohibición - conciencia de la antijuridicidad - culpabilidad

\section{The appreciation of the cultural valuation in the mistake of law}

\begin{abstract}
This article explores the role of the particular cultural valuation in the context of the mistake of law, from the standpoint of the theory of norms, defending the viewpoint that the judge is legally obligued to weigh this cultural valuations in his decision. The author presents a concept of mens rea (vision de la antijuridicidad) and on this ground the author presents the conceptual delineation of the necessary conditions tu afirm the presence of mens rea (conciencia de la antijuridicidad). Within this framework the author suggests the reformulation of the requirements of mens rea, into a gradual nomenclature regarding the following classification: conocimiento (knowledge), comprehension (comprension) and internalization (internalización). It's also developed the idea of a complementary defense as a defense strategie in the context of a cultural defense, as long as it's defined as the existence of a differenced evaluative cosmovision of the person who commits the crime.
\end{abstract}

$$
\text { Mistake of law - mens rea - culpability }
$$

* Abogada, Legum Magister por la Universidad de Friburgo, Alemania. Correo electrónico: alecastilloara@gmail.com

Este artículo constituye una versión revisada de la parte general de la tesis de magíster, que fuera evaluada con máxima distinción, y cuyo título original era "Kulturelle Wertvorstellungen im Bereich des Verbotsirrtums. Eine rechtsvergleichende Analyse Deutschlands, Chiles und der USA", tesis dirigida por Prof. Dr. Dr.h.c.mult. Ulrich Sieber.

Artículo recibido el 8 de diciembre de 2013 y aceptado para su publicación por el Comité Editorial el 29 de octubre de 2014 


\section{INTRODUCCIÓN}

L as diferencias culturales en una sociedad moderna son una realidad, y eso necesariamente presenta desafíos para el Derecho. Ya sea en razón de los movimientos migratorios, de la globalización o bien de repercusiones aún no resueltas de los efectos del colonialismo. Como sea, el afrontar los problemas que el pluralismo a nivel jurídico conlleva es un verdadero desafío de los estados de Derecho modernos ${ }^{1}$.

Los desafíos de este fenómeno en el ámbito jurídico se fundamentan en dos ideas centrales. Por una parte, en la idea de que los destinatarios de las normas son ante la ley -en abstracto- iguales, y esa igualdad es una igualdad que debe ser concebida en términos de igualdad relativa y no absoluta. Por otra parte, en la concepción de la norma en tanto acción comunicativa (kummunikative Handlung) ${ }^{2}$, que plantea necesariamente dificultades interpretativas, especialmente si el destinatario de la norma proviene de un ordenamiento jurídico distinto a aquel en que rige dicha norma y, por tanto, pertenece a un ordenamiento de normas culturales también distintas ${ }^{3}$. O bien si es que el destinatario de la norma aun cuando no pertenezca a un ordenamiento jurídico distinto tiene patrones de orientación normativos y valoraciones distintas debido a una socialización exótica ${ }^{4}$, o a un desarrollo extremadamente aislado de la sociedad mayoritaria 5.

${ }^{1}$ No por nada es la cultura y el Derecho el tema elegido para el Deutscher Juristentag (el día jurídico alemán o bien la jornada jurídica alemana) del 2014, y es hoy el tema que ocupa a gran parte de la dogmática de avanzada en dicho país. Especialmente motivados por la resolución del Tribunal de Colonia en relación con el reconocimiento explícito de la concurrencia de un error de prohibición invencible en razón de las valoraciones culturales diferenciadas de los imputados por el delito de lesiones, a raíz de la circuncisión consentida por los padres de un menor de origen musulmán. Lo central de este caso es que puso en el centro de la discusión penal el problema de las valoraciones culturales. Pues, por una parte, se reconoció que la circuncisión de un menor aun con el consetimiento de los padres constituye un injusto penal en razón de los $\S \S 223$ inc. 1, 224 inc. 1 Nr. 2 del StGB que tipifica las lesiones; pero además aceptó la causal de exculpación en virtud de un error invencible determinado por las valoraciones culturales diferenciadas del autor del hecho. LG Köln, Urteil de 07.05.2012, BeckRS 2012, 13647, Anmerkung Krug, FD-StrafR 2012, 334654. Cabe destacar que luego de la resolución del Tribunal de Colonia se envió un proyecto de ley que regulaba específicamente los casos de circuncisión masculina de motivación religiosa. Dicho proyecto se materializó en ley y vio la luz el 28 de diciembre de 2012. Se establece en esta ley lo siguiente: "En consiguiente se regula, que durante los primeros 6 meses desde el nacimiento del hijo se puede realizar la circuncisión del mismo, incluso por una persona que pertenezca a la comunidad religiosa en cuestión, siempre que esta se haya preparado especialmente para ello y para la ejecución de la circuncisión esté capacitado de manera análoga a la que un doctor o una doctora lo estaría”.

${ }^{2}$ Habermas, J., Vorstudien und Ergänzungen zur Theorie des kommunikativen Handelns, Suhrkamp, Fráncfort, 1995, p. 329.

${ }^{3}$ Valerius, B., Kultur und Strafrecht, Duncker \& Humblot, Berlin, 2011, p. 173.

${ }^{4}$ Jakobs, G., Derecho Penal Parte General, Marcial Pons, Madrid, 1997, p. 659.

5 En este sentido Fikentscher ejemplifica las dificultades interpretativas subjetivas por medio de la idea del concepto "must" (deber) y señala: "Existen diferencias culturales en la comprensión legal de la palabra 'must'. Cuando la luz de un semáforo para peatones muestra rojo, un alemán no va a cruzar la calle, aun cuando sea tarde por la noche, no haya tráfico ni tampoco vengan personas, pues él está educado para entender que la ley que señala 'no cruces con rojo' ha sido decidida en el Parlamento o Consejo que es parte de la democracia franquista (...) de manrea tal que los ciudadanos se encuentran en una relación de 
La coexistencia de ideologías diferenciadas, la segregación y falta de identificación de grupos respecto de la identidad cultural mayoritaria, así como la dominación de esta con relación a la toma de decisiones y políticas de Estado llevan necesariamente a la creación de conflictos entre la minoría en relación con la mayoría.

La pregunta que se plantea entonces es ¿cuál es el rol del Derecho penal en esta materia? ¿Debe una sociedad plural tratarse con criterios diferenciados en atención a la diversidad de destinatarios que coexisten en los ordenamientos jurídicos vigentes? O bien ¿debe la aplicación e interpretación de normas mantener un estándar objetivo en atención a criterios preventivos con indiferencia de sus destinatarios, pues ese es un problema de la creación y no de la aplicación de las leyes en tanto directrices vinculantes? El problema de las sociedades polarizadas y su coexistente diversidad ideológica puede llevar al actuar errático y confuso de los destinatarios de las normas jurídicas. Las razones de esto pueden deberse a dos motivos: ya sea a una comprensión deficitaria de las normas jurídicas, o bien a una internalización deficitaria de las mismas, desencadenando entonces la existencia de un posible error de prohibición como causal exculpatoria.

\section{CONSIDERACIONES PREVIAS RESPECTO DE LA RELACIÓN ENTRE DERECHO Y CULTURA}

\section{La relación entre Derecho penal y cultura}

Cultura y Derecho se encuentran en una relación simbiótica. Una de las tareas de los ordenamientos jurídicos actuales es adaptarse sistemáticamente tanto a las variaciones culturales así como a los cambios sociales que viven los ordenamientos. Esto es consistente a su vez con la reformulación de la concepción del bien jurídico como justificación de las normas penales que suele ser atribuida a Hörnle. Sostiene esta penalista que la idea del bien jurídico se explica mucho mejor en algunas disposiciones legales con el título "protección de identidades culturales", que con la idea de "protección de bienes jurídicos" 6 . Y el pensamiento subyacente es el siguiente: porque el Derecho penal es por naturaleza restrictivo de la libertad de los individuos, en tanto estos ceden porciones

reciprocidad con el órgano (...). En los EE.UU., un símbolo de no estacionar no representa necesariamente una prohibición real de estacionar, pero sí una amonestación de estacionar ahí para evitar tener una multa (...). Esto lleva a una lectura mucho menos estricta de obediencia por parte de quien se encuentra unilateralmente vinculado por la norma. De ahí que, es bastante lógico, que frente al edificio de las Naciones Unidas de Nueva York, haya símbolos de tráfico adicionales, al lado de los típicos símbolos de no estacionar que dicen: 'Ni se le ocurra estacionar aquî'”. Fikentscher, W., Law and Antbropology, Verlag der Bayerischen Akademie der Wissenschaften, Múnich, 2009, p. 233.

${ }^{6}$ Hörnle, T., "Strafrechtliche Verbotsnormen zum Schutz von kulturellen Identitäten”, en Dreier, H. y Hilgendorf, E., (coord.), Kulturelle Identität als Grund und Grenze des Rechts, Nomos, Stuttgart, 2008, p. 321. En este sentido también Hörnle, T., Grob anstößiges Verbalten. Strafrechtlicher Schutz von Moral, Gefüblen und Tabus, Klostermann, Fráncfort, 2005, pp. 11 ss. 
de su libertad para tener más libertad, es que la fundamentación de las normas penales tienen su justificación en la necesidad de proteger ciertos bienes jurídicos ${ }^{7}$.

La discusión acerca de la existencia de normas penales que no protegen bienes jurídicos es legión en la doctrina, clásicos ejemplos son las normas que prohíben la homosexualidad, las normas que prohíben el incesto, la bigamia, entre otras. Estas, más que proteger un bien jurídico determinado, protegen una moral social de pocos. La pregunta entonces es ¿dónde queda la justificación de la conminación penal de este tipo de disposiciones?

Se consagra esta simbiosis en la idea de que las normas penales determinan el comportamiento de los destinatarios de las normas y, en este sentido, tienen por finalidad evitar los comportamientos culturales desviados o indeseados por la cultura dominante que es, en definitiva, la que define las directrices del pacto social ${ }^{8}$.

\section{2. ¿Cultura o identidad cultural?}

La Enciclopedia Brockhaus define al concepto cultura de la siguiente manera: "En su sentido más amplio se puede designar con el concepto de cultura, lo que el hombre ha logrado, lo que en definitiva no le es dado por la naturaleza..." 9 . Se entenderá a la cultura como contraposición a la naturaleza, es decir, naturaleza como condición preexistente que no es producto del hombre ${ }^{10}$. Se podría sostener entonces que cultura tiene un significado equivalente a civilización, sin embargo, el concepto ha tenido una consecuente evolución en la integración de su contenido. Una de las primeras precisiones del término "cultura" fue entregada por Samuel Pufendorf, quien entiende a la cultura como las condiciones de vida que diferencian a los hombres de los animales ${ }^{11}$, para él cultura es lo que marca el paso del estado de naturaleza al contrato social ${ }^{12}$.

Immanuel Kant es quien replantea el concepto, y entiende que pertenecen a la cultura los modales y la moral como elementos determinantes. La cultura abarca la idea de la moralidad que se encuentra en el interior del ser humano, y se va refinando junto a la evolución del mismo ${ }^{13}$. Un planteamiento más moderno es el que tiene Luhmann, quien entiende a la cultura como la memoria de la sociedad. Para Luhmann no es la cultura un estado proporcionado o un mero presupuesto de la naturaleza, sino que es

${ }^{7}$ Roxin, C., Allgemeiner Teil, C.H. Beck, Múnich, 2006, pp. 16 ss.

${ }^{8}$ Hörnle (nota 7 "Strafrechtliche..."), p. 322.

9 Enciclopedia Brockhaus, "In seiner weitesten Verwendung kann mit dem Begriff Kultur alles bezeichnet werden, was der Mensch geschaffen hat, was also nicht naturgegeben ist...”, Volumen 16, Kultur, Brockhaus, Wiesbaden, 1976, p. 61.

${ }^{10} \mathrm{Al}$ respecto véase Valerius (nota 4), p. 28.

${ }^{11}$ Pufendorf, S., De jure naturae et gentium, Sumptibus Friderici Knochii, Fráncfort, 1694, pp. 398 ss.

12 Valerius denomina a esta interpretaciónn como "el límite entre cultura y barbarie". Valerius (nota 4) p. 28.

13 Kant, I., Werkausgabe, Bd. IX: Schriften zur Naturphilosophie, Wissenschaftliche Buchgesellschaft, Fráncfort, 1983, p. 44. 
el resultado de la sociedad misma en tanto entidad organizada ${ }^{14}$. Reviste la cultura la característica de una forma de vida propia de un grupo determinado, es decir, cultura como pertenencia a un grupo (Gruppenzugebörigkeit).

Cultura puede también concebirse como una forma de vida inicial, variable, evanescente de naciones, pueblos y comunidades ${ }^{15}$. Esta línea de pensamiento tiene como principal exponente a Herder, y tiene como presupuesto básico que los conceptos de cultura y pluralismo se encuentran indefectiblemente en una relación complementaria $^{16}$. Esta interpretación de cultura opera con la lógica de que hay una visión de mundo existente, una cosmovisión, que marca la diferencia entre una cultura y otra ${ }^{17}$. Es la sensación de pertenencia y de destino común (Schicksal), la característica determinante de estos grupos. Esto se ilustra fácilmente con el fenómeno de la Unión Europea: todos los Estados miembros pertenecen a una comunidad, con leyes vinculantes para todos -ya sea Estados o individuos-, pero alemanes, italianos, griegos, etc., no tienen una identidad cultural, no tienen la misma construcción valorativa ${ }^{18}$. Y es precisamente esta construcción valorativa la que juega un rol determinante al momento de evaluar la concurrencia de un error de prohibición en el caso concreto.

El concepto de cultura obedece a distintas acepciones, y es un concepto mutable en el tiempo. Sin embargo, para la categoría que al Derecho penal en el ámbito del error de prohibición interesa, es la idea de cultura en tanto identidad cultural a lo que se alude. Identidad cultural significa pertenencia a un grupo (Gruppenzugebörigkeit $)^{19}$, y este grupo tiene -a diferencia de otros- patrones de significado específicos (spezifisches Bedeutungsmuster), y esos patrones varían de identidad cultural en identidad cultural. Dotando a estos grupos de una cosmovisión particular del orden de las $\cos ^{20}{ }^{20}$, de lo bueno y lo malo, de lo justo y lo injusto, etc. ${ }^{21}$ En adelante, toda vez que se haga referencia a cultura, de lo que se trata es de la identidad cultural de un grupo de personas determinado, que detentan patrones de valoración similares y una cosmovisión de mundo particular. Esto se relaciona con la precisión que hace Hörnle en atención al concepto de cultura que al Derecho penal interesa, y señala "que de acuerdo a la construcción subjetiva propia de los hombres, la identidad cultural se vuelve una concepción de sí

${ }^{14}$ Sawilla, J., Luhmanns Kulturbegriff unter besonderer Berücksichtigung der Gedächtnisproblematik, Grin Verlag, Norderstedt, 2011, pp. 3 ss.

15 Perpeet, W., “Kultur, Kulturphilosophie”, en Ritter, J. y Gründer, K. (coord.) Historisches Wörterbuch der Philosophie, Volumen 4, Wissenschaftliche Buchgesellschaft, Darmstadt, 1976, pp. 1309 ss.

${ }^{16}$ Hörnle (nota 7 "Strafrechtliche..."), p. 316.

${ }^{17}$ Bollacher, M., Der junge Goethe und Spinoza. Studien zur Geschichte des Spinozismus in der Epoche des Sturms und Drangs, Max Niemeyer Verlag, Tubinga, 1969, pp. 334 ss.

18 En este mismo sentido Möllers, C., "Pluralität der Kulturen als Herausforderung an das Verfassungsrecht?”, en Dreier, H. y Hilgendorf, E., (coord.), Kulturelle Identität als Grund und Grenze des Rechts, Nomos, Stuttgart, 2008, p. 224.

${ }^{19}$ Como bien señala Fikentscher, "solo se puede hablar de cultura cuando hay gente suficiente que se identifica con esa cultura”. Fikentscher (nota 6), p.113.

${ }^{20}$ Hörnle (nota 7 "Strafrechtliche..."), p. 318.

21 Ibid. 
mismos"22. A su vez, diferencia Hörnle entre identidad cultural en sentido amplio e identidad cultural en sentido restringido ${ }^{23}$. En sentido restringido se refiere la identidad cultural a los factores culturales que tienen una significación especial para el núcleo de la personalidad del ser humano. En sentido amplio e refiere a la adopción de las convenciones morales de la comunidad como patrones aceptados de comportamiento ${ }^{24}$. En adelante se hará referencia a la cultura en tanto identidad cultural, tanto en sentido amplio como en sentido restringido indistintamente.

\section{ANÁlisis DE LAS CONSIDERACIONES CULTURALES EN EL ÁMBITO POLÍTICO CRIMINAL}

\section{El compromiso desde la creación de la ley}

La problemática de la valoración de los factores culturales podría quedar resuelta de manera basal si es que se ponderaran los factores culturales en el momento de la creación legislativa, mediante la incorporación tanto en la discusión legislativa así como en la toma de decisiones de representantes de grupos que detenten una identidad cultural diversa. Mientras más diversa y amplia sea la gama de los representantes de estas minorías a nivel legislativo, más representativo se vuelve el proceso de creación de la normativa vinculante. Esta medida permitiría eliminar con anticipación los reproches respecto de la inclusión de la diversidad cultural y de las minorías étnicas que coexisten bajo un mismo sistema de normas, pues esta visión se incorporaría de manera originaria en la creación del Derecho. Un ejemplo de esta medida es el caso de Noruega y el Parlamento del pueblo lapón o también llamado sami, quienes desde 1989 tienen reconocimiento constitucional y una representación estable en el Congreso Nacional ${ }^{25}$.

Manifestación de esto es también lo señalado en el Convenio 169 de la OIT acerca de pueblos indígenas y tribales, cuyo artículo 2 señala: "1. Los gobiernos deberán asumir la responsabilidad de desarrollar, con la participación de los pueblos interesados, una acción coordinada y sistemática con miras a proteger los derechos de esos pueblos y a garantizar el respeto de su integridad”. La incorporación de las minorías en la discusión parlamentaria es una de las medidas que podría salvar el problema de las valoraciones culturales. No solo eso, pues dotaría a las normas de consideraciones intersubjetivas que de otra manera no tendrían, lo que permitiría una mejor socialización y recepción de las mismas, sino que también esto dota a las normas de una legitimidad democrática que de lo contrario no tendrían ${ }^{26}$. En lo que sigue, sin embargo, este trabajo no se enfocará

\footnotetext{
${ }^{22}$ Ibid.

23 Ibid.

${ }^{24}$ Ibid.

25 The International Sami Journal, disponible en www.baiki.org.

${ }^{26}$ Mayer, M.E., Rechtsnormen und Kulturnormen, Wissenschaftliche Buchgesellschaft, Darmstadt, 1965,
} p. 25 . 
en el análisis que se pueda hacer en materia de creación de leyes penales, sino que en relación con la aplicación de las mismas y la discusión que esta desata al momento de determinar la procedencia o improcedencia de las valoraciones culturales en el contexto de un error de prohibición.

\section{La incorporación de la ley extranjera al Derecho nacional}

Reviste especial relevancia en este análisis mencionar el problema histórico de la introducción de normativa de Derecho comparado al Derecho nacional sin atención a criterios particulares de la sociedad receptora de dicha legislación, ejemplos de esto son la importación de normas propias del Derecho alemán al Derecho chileno, o bien del Derecho suizo y su casi absoluta reproducción del Código Penal en el sistema jurídico turco, etc. ${ }^{27}$ Lo dramático es que la introducción de dicha normativa pareciera hacerse sin consideración al destinatario. Es evidente que el Código Penal suizo entrará en conflicto con la realidad extremadamente religiosa que existe en Turquía, pues hay aplicación paralela de las reglas contenidas en la Sharia. Esto sumado a la falta de identidad de grupo que revisten las sociedades actuales debido al pluralismo latente, hace que las normas se vuelvan poco representativas e inaccesibles para gran parte de la sociedad. En este sentido se podría afirmar que mientras más influencia externa tenga una sociedad, ya sea por medio de inmigrantes con ideologías diversas o bien por el contacto con medios de comunicación internacionales, es decir, el intercambio comunicacional a nivel mundial, menos se puede hablar de la identidad ideológica de un grupo étnico. De ahí entonces que el concepto cultura se vuelva insuficiente y sea necesario acotarlo a la idea de identidad cultural.

\section{El rol de las normas y la ficción del conocimiento de las mismas}

a. Las normas como actos de habla

Las normas son actos comunicativos, y como actos comunicativos que son pertenecen a un determinado sistema de símbolos. Este sistema de símbolos es el lenguaje ${ }^{28}$. El lenguaje en el ámbito jurídico penal tiende a ser un impedimento, pues este sistema de símbolos pertenece además a un tipo especial de lenguaje que es el lenguaje jurídico, un lenguaje técnico, pero que debe ser comprendido tanto por legos como por expertos ${ }^{29}$. Las

27 Zimmermann, R., "Römisches Recht und europäische Kultur”, en Dreier, H y Hilgendorf, E. (coord.), Kulturelle Identität als Grund und Grenze des Rechts, Nomos, Stuttgart, p. 32.

${ }^{28}$ Habermas (nota 3).

${ }^{29}$ Como bien señala Schünemann en relación con el problema de la prohibición de analogía, que el problema subyacente es que el legislador utiliza un lenguaje técnico (Fachsprache), el que llegado cierto punto implica que nosotros de acuerdo con criterios jurídicos traduzcamos el sentido de dicho lenguaje en nuestro lenguaje coloquial (Umgangssprache) como metalengua. Schünemann, B., Nulla poena sine lege?, de Gruyter, Berlin, 1978, pp. 18-19. 
normas jurídicas son para el lego, para el ciudadano no experto, de difícil comprensión y esta dificultad se agrava cuando el destinatario de la norma no solo es lego, sino que además pertenece a un grupo minoritario con valoraciones jurídicas distintas al grupo mayoritario o dominante en una sociedad. Esta dificultad en el traspaso de información al destinatario de la norma alcanza otro nivel de complejidad, si al problema de la complejidad del lenguaje jurídico agregamos que la persona además de ser un lego, de pertenecer a una etnia o grupo con valoraciones culturales diferenciadas, no domina el idioma oficial del lugar. El caso paradigmático del extranjero.

Como bien señala Max Ernst Mayer: "La afirmación de que la ley se dirige al pueblo se encuentra con la indiscutida verdad de que el pueblo no conoce las normas jurídicas" 30 , pero no solo por su falta de socialización sino que por su falta de comprensión. La razón de esto obedece a que "solo a través de un arduo estudio puede penetrarse el sentido de las leyes, de modo que el lego que las lee, no las entiende, de lo que resulta que nuestras leyes deberían estar redactadas de un modo fundamentalmente diverso si ellas correspondieran en alguna medida a la concepción de que constituyen directrices para los súbditos" ${ }^{31}$. El problema de fondo radica en que los sistemas penales para ser realmente sistemas vinculantes deben considerar las particularidades culturales de los destinatarios de las normas, pues solo así se podría afirmar que un determinado sistema penal se encuentra en consonancia con una sociedad pluralista y democrática propia de un Estado de Derecho.

\section{b. Los dos destinatarios de las normas}

Las normas se dirigen, en principio, a dos destinatarios distintos: al juez o experto; y al ciudadano o lego. Las normas, por lo tanto, son sometidas por sus destinatarios necesariamente a procesos interpretativos y, por consiguiente, a resultados interpretativos distintos. El juez, por una parte, considera a las normas como Derecho objetivo ${ }^{32}$. El ciudadano, por su parte, considera a las normas como prohibiciones o mandatos, cuyo sentido se determinará por estándares subjetivos de interpretación, esto es su criterio o lo que él entiende luego de su proceso interpretativo interno. Habrá tantas interpretaciones como destinatarios de las normas existan. Este problema de la falta de estandarización de criterios interpretativos que tiene lugar entre legos y expertos, se vuelve aún más complejo si consideramos que esto tiene lugar en sociedades extremadamente pluralistas. En este contexto es frecuente entonces que exista la ya mencionada figura del error de prohibición, cuando la comprensión subjetiva de las normas por parte del autor, y el contenido objetivo de las mismas se encuentran en una discordancia inconsciente ${ }^{33}$.

Las normas tienen, por otra parte y especialmente en el Derecho penal, una función de garantía: las normas garantizan la libertad ciudadana ${ }^{34}$. La libertad de los individuos

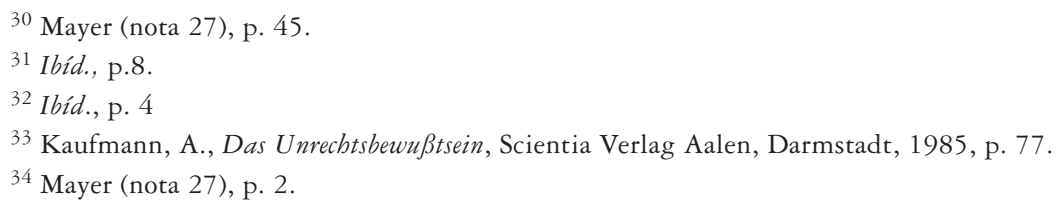


es protegida por el Estado, pues solo con la existencia de normas penales efectivas es concebible la sociedad civil en sentido moderno. Pero las normas tienen a su vez una función protectora del Estado, en el sentido que limitan el poder estatal, ello, en virtud del monopolio de la fuerza puede fácilmente llevar a un comportamiento arbitrario ${ }^{35}$. Esto es claro en el ámbito constitucional, donde los derechos fundamentales actúan como limitaciones al ejercicio del poder estatal y, por tanto, como freno a eventuales arbitrariedades $^{36}$. Pero ¿existe tal limitación a nivel legal? Una limitación formal que tiene el Estado en el ejercicio de la función penal (ius puniendi) es precisamente la consagración de principios constitucionales que limitan su función, y son en particular los siguientes: el principio de culpabilidad, el principio de proporcionalidad y el principio de legalidad, estos regulan la función del Estado en tanto entidad que detenta el monopolio de la fuerza ${ }^{37}$.

Es necesario entonces volver sobre la importancia que tiene el principio de legalidad en el ámbito del error de prohibición, en especial, en su mandato de precisión (Bestimmtheitsgebot). Una ley que obedece el principio de legalidad, es vinculante y habilita, en principio, para sancionar a quien infrinja dicha ley, siempre que dicha ley sea precisa tanto en su descripción de las normas de comportamiento de dicho precepto, así como en la penalidad cuya inobservancia acarrea ${ }^{38}$.

El mandato de precisión se dirige principalmente al juez y lo vincula en sus decisiones futuras en tanto limita las opciones interpretativas en razón de la ley formal ${ }^{39}$. Según Jescheck, se satisface este principio siempre que la ley tome en consideración todas las circunstancias que permiten trazar el límite entre absolución y condena ${ }^{40}$. De lo anterior se sigue que en el ámbito del error de prohibición la interpretación de las normas juega un rol fundamental, y esta interpretación, ya sea que provenga del juez o de los ciudadanos no expertos, no es más que la comprensión de la norma. La interpretación de la ley que cada individuo detenta es el equivalente a la comprensión de la misma. Esta idea de la comprensión resulta central si uno entiende que el error de prohibición opera relativo a la siguiente premisa: una pena puede ser impuesta únicamente cuando el autor del hecho delictivo ha tenido la posibilidad de ser motivado por esta norma ${ }^{41}$. Pero lo que el destinatario de la norma no pudo comprender de acuerdo con la expectativa que el experto tenía de él, no puede motivarlo o surtir efecto alguno. Es crucial establecer una diferencia entre lo que es el conocimiento de la norma y la comprensión de la misma, pues no son términos intercambiables o equivalentes ${ }^{42}$. Es por ello que se puede afirmar que el conocimiento de la ley es una mera ficción que no se condice con

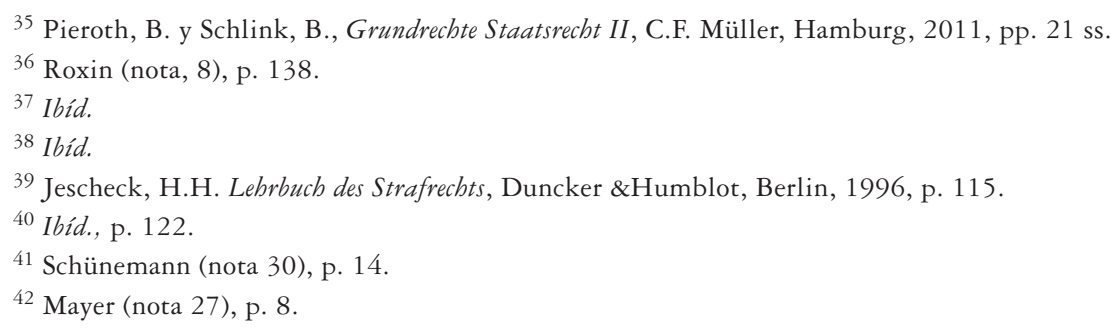


lo que es la comprensión de la misma. Según Mayer, así como el pueblo no sabe nada de la ley, pues la ley vigente tampoco sabe nada del pueblo, y los dos simplemente no se conocen ${ }^{43}$.

\section{ANÁlisis DOGMÁTICO DE LAS VALORACIONES CULTURALES EN LA ESTRUCTURA DEL DELITO}

Hasta aquí se ha tematizado cuál es la relevancia de las consideraciones culturales en el ámbito del Derecho penal y de la teoría de las normas, así como su relación con el error de prohibición. Relativo a esta base se hará en lo que sigue una revisión de los ámbitos de la teoría del error en particular, en los que es factible que tenga lugar la ponderación de las valoraciones culturales diferenciadas.

\section{La conciencia de la antijuridicidad \\ a. Concepto}

La conciencia de la antijuridicidad designa al conocimiento intelectual del autor de que su comportamiento es contrario a Derecho. Según la doctrina mayoritaria no es necesario el conocimiento de la penalidad de un comportamiento determinado, pero sí es presupuesto necesario que el autor reconozca ese acto como un acto que afecta o pone en peligro un bien jurídico protegido por el Derecho. La doctrina mayoritaria señala como suficiente que haya conocimiento de la antijuridicidad material ${ }^{44}$. Aquí se habrá de sostener, sin embargo, que el conocimiento aparece como estándar insuficiente para afirmar conciencia de la antijuridicidad. La exigencia debe situarse en el plano del entendimiento, en el plano de la comprensión y solo así se puede afirmar conciencia de la antijuridicidad por parte del autor. Se propone una reformulación conceptual en el entendido que habrá conciencia de la antijuridicidad, siempre que haya comprensión intelectual del autor respecto de su comportamiento como un comportamiento contrario a Derecho.

La conciencia de la antijuridicidad se define como un elemento integrante pero independiente de la culpabilidad. Lo relevante de esto es que el contenido de la culpabilidad es dependiente de las visiones culturales dominantes (der Schuldinhalt hängt von den herrschenden Kulturanschauungen $a b)^{45}$. Por lo mismo es que es de relevancia la relación que existe entre conciencia de la antijuridicidad y valoraciones culturales acentuadas de ciertos individuos que detentan una identidad cultural particular ${ }^{46}$. Que la cosmovisión cultural determina el acceso a la conciencia de la antijuridicidad es un hecho. Lo que

\footnotetext{
${ }^{43}$ Ibid., p. 9.

${ }^{44}$ Neumann, U., “\$17 Verbotsirrtum”, en Kindhäuser, U., Neumann, U. y Paeffgen, H.U. (coord.), Nomos Kommentar, Nomos, Baden-Baden, 2005, p. 580.

45 Kaufmann (nota 34), p. 23.

46 Ibid.
} 
queda por determinar es si el juez está obligado, y si es así por qué y cómo, a ponderar en la decisión judicial estas valoraciones culturales particulares; o bien, si es que esa ponderación implica necesariamente un debilitamiento de la validez de las normas y, por tanto, una directa repercusión en tanto la efectividad de las mismas bajo un criterio de prevención general positiva. El peligro radica entonces en que la apertura a la ponderación obligatoria de las valoraciones culturales se transforme en un sleepery slope, es decir, que se vuelva una subjetivación excesiva de las normas penales, acarreando un déficit preventivo de las mismas ${ }^{47}$. Esta es la objeción paradigmática que se hace en el contexto de la ponderación de las valoraciones culturales diferenciadas ${ }^{48}$, pero también en el caso de la aplicación de un error de prohibición que prescinde de dichas consideraciones ${ }^{49}$. El argumento del sleepery slope es precisamente el miedo que existe a que el reconocimiento progresivo y excesivamente amplio de la figura exculpante del error de prohibición lleve a un debilitamiento de las normas penales en tanto directrices de comportamiento sancionadas con pena deteriorando su estabilidad. Lo que esta objeción obvia, es que en un análisis de determinación de la pena, la mirada retributiva es inevitable y en este sentido si falta la culpabilidad ya sea porque no existe comprensión o internalización de las normas, la imposición de la pena bordea los terrenos del utilitarismo. El argumento de quienes ven en la apertura a las valoraciones culturales un debilitamiento de la norma es insatisfactorio, pues no se puede ponderar con mayor peso específico la calidad ejemplificadora de la pena como castigo, con cargo a una afectación al principio de culpabilidad como presupuesto y límite de la imposición individual de la pena ${ }^{50}$.

\section{b. Factores influyentes}

Es elemento central de la conciencia de la antijuridicidad el conocimiento de la permisión o prohibición de una determinada conducta por parte del ordenamiento jurídico-penal. Esto plantea, sin embargo, la pregunta por el estándar de exigencia para afirmar conciencia de la antijuridicidad. Para poder fijar el parámetro de exigencia es necesario partir de la premisa de que conocimiento, comprensión e internalización no son conceptos intercambiables, no son sinónimos, y entre ellos existe una relación gradual $^{51}$.

${ }^{47} \mathrm{Kim}, \mathrm{N}$., "The cultural defense and the problem of cultural preemtion: a framework for analysis", New Mexico Law Review 27, p. 114.

${ }^{48}$ Köhler, M., Strafrecht Allgemeiner Teil, Springer, Berlin, 1997, p. 434.

${ }^{49}$ Neumann (nota 45), p. 704.

${ }^{50}$ Como argumentos complementarios para el rechazo de las valoraciones culturales diferenciadas se ha sostenido que su admisibilidad conlleva en sí misma un desconocimiento al principio de igualdad, pues su consideración podría entenderse como un privilegio, así como también se ha esgrimido la falta de precedente jurídico en el contexto del Derecho europeo que contemple figuras que incorporen las valoraciones jurídicas diferenciadas. Torres, E., "Identidad, creencias y orden penal: la eximente cultural”, en López, A. y Aguado, C. (coord.), La protección de bienes jurídicos globales, Anuario de la Facultad de Derecho de la Universidad Autónoma de Madrid, N 17, 2013, p. 420.

${ }^{51}$ Córdoba Roda, J., El conocimiento de la antijuridicidad en la teoría del delito, Bosch, Barcelona, 1962, pp. 101 ss. 
Es posible que el autor tenga conocimiento de que existe una norma determinada, que entienda su contenido, pero que este contenido se vea determinado por su valoración cultural particular y sea deficiente. O bien, es posible que su cosmovisión de los parámetros de intereses jurídicamente valiosos sea divergente respecto de los que dominan en su realidad cultural y que, por tanto, tenga una deficiente internalización de las normas.

A continuación, una revisión de estos tres conceptos, estos, si bien planteados por la doctrina, no han logrado ser esquematizados de manera correcta ${ }^{52}$.

\section{aa) El conocimiento de la antijuridicidad}

No se refiere al conocimiento acerca de una disposición específica, sino que referente a la afectación de un determinado bien jurídico. La doctrina mayoritaria sostiene que es irrelevante el conocimiento de la penalidad, así como el conocimiento de la dañosidad a la moral o bien el conocimiento de la dañosidad social, debido a su variabilidad e imprecisión $^{53}$. Es exigir demasiado cuando se exige el conocimiento de la penalidad, pero es exigir muy poco cuando se exige simplemente el conocimiento de la dañosidad social o de la dañosidad moral. De esta manera el punto intermedio entre estas dos concepciones lo entrega la idea de la antijuridicidad material ${ }^{54}$, esto es conocimiento de una afectación de bienes jurídicos socialmente nociva ${ }^{55}$, o bien de una afectación material-concreta ${ }^{56}$.

El concepto conocimiento es por cierto impreciso, pues se puede conocer la afectación o el daño que se produce por medio de un comportamiento, pero el significado que dicho comportamiento tiene para el ordenamiento jurídico puede no comprenderse. La dañosidad en tanto afectación de bienes jurídicos está dotada de significado y el conocimiento teórico de la noción de dañosidad es muy superficial para afirmar antijuridicidad, luego conocimiento si no es entendido en términos de comprensión, simplemente pierde su sentido de fondo y se vuelve un parámetro meramente formal que no se condice con la realidad material. El conocimiento se orienta siempre desde la esfera del lego, desde la esfera del profano ${ }^{57}$, y por lo mismo es que el contenido -en términos de noción de

52 En la doctrina alemana, identifican el problema Jakobs y Köhler, sin embargo, ninguno de los dos logra por sí solo esquematizar y realizar una sistematización gradual de estos tres conceptos en relación con la visión de la antijuridicidad. Jakobs (nota 5), Köhler (nota 49), pp. 402-433.

53 Neumann (nota 45), pp. 572-610. Roxin (nota 8), p. 589.

${ }^{54}$ Baumann, J., Weber, U. y Mitsch, W., Strafrecht Allgemeiner Teil, Gieseking, Bielefeld, 2003, pp. 48 ss. Kindhäuser, U., Strafrecht Allgemeiner Teil, Nomos, Baden-Baden, 2011, p. 228. Neumann (nota 45), p. 580. Maurach, R. y Zipf, H., Strafrechts Allgemeiner Teil, C.F. Müller Juristischer Verlag, Heidelberg, 1985 , p. 525. Roxin (nota 8), p. 589. Rudolphi, H.J., Unrechtsbewußtsein, Verbotsirrtum und Vermeidbarkeit des Verbotsirrtums, Verlag Otto Schwarz \& Co., Göttingen, 1969, pp. 53-54. Binding, por su parte, es de la idea contraria, pues es defensor de una doctrina ultrapositivista de la conciencia de la antijuridicidad, identifica a esta con un estricto formalismo, donde la antijuridicidad material aparece como criterio insatisfactorio, Binding, K., Die Normen und ibre Übertretung I, Verlag von Felix Meiner, Leipzig, 1916, pp. 42 ss.

55 Roxin (nota 8), p. 601.

${ }^{56}$ Groteguth, T., Norm- und Verbots- (Un-) kenntnis, Duncker und Humblot, Berlin, 1993, p. 124.

${ }^{57} \mathrm{La}$ idea de la valoración paralela en la esfera del profano es una idea que se oirigna en Binding, K., Die Normen und ibre Übertretung III, Wilhelm Engelman, Leipzig, 1918, p. 148, que ha sido seguida por la 
afectación en tanto antijuridicidad material- de una norma siempre pasa también por el filtro del análisis interpretativo que hace el profano. Esta interpretación permite confirmar que lo que hay es comprensión, entendimiento y no mero conocimiento ${ }^{58}$. Una reformulación correcta entonces del estándar de acceso a la antijuridicidad es situarlo en el plano de la comprensión (Verständnis) y no del conocimiento (Kenntnis) de la antijuridicidad material.

bb) La comprensión de la antijuridicidad

El criterio hasta ahora seguido por la doctrina mayoritaria que sitúa el estándar de exigencia en el conocimiento de la antijuridicidad debe ser reformulado. Un conocimiento no es más que un acercamiento indiciario y superficial a lo que es la conciencia de la antijuridicidad en su sentido material, pero no da cuenta de la exigencia real que está en el plano del entendimiento.

Ejemplo:

El autor (A) conoce el presupuesto de que la vida es un bien jurídicamente valioso, y que por tanto el homicidio de otro ser humano $(\mathrm{H})$ se encuentra prohibido -no obstante, no sepa cuál es la norma específica que prohíbe dicha conducta, o cuál es la penalidad que acarrea su incumplimiento-. A pesar de ello cree A que la vida de $\mathrm{H}$, que se encuentra en estado vegetal no es una vida valiosa ni menos una vida digna y le proporciona una inyección letal. A, aduce en su defensa la consideración de razones humanitarias en su actuar, al entender que ponderó que ese tipo de vida no era una vida valiosa y que era indigno mantener a $\mathrm{H}$ vivo a toda costa, en tanto eso implicaba un tratamiento indigno de H. En este caso es la identificación del bien jurídico vida -como interés jurídicamente valioso, protegido por el Derecho- acertada. Pero el autor yerra en la comprensión de ese bien jurídico pues no lo entiende como un bien jurídico indisponible ${ }^{59}$ y absoluto ${ }^{60}$, sino que lo somete a ponderación, cuestión que está proscrita por la doctrina mayoritaria ${ }^{61}$. La comprensión que tiene el sujeto es imprecisa y lo induce a error en su actuar.

De esto se sigue que hay que distinguir dos casos que pueden concurrir en este supuesto de error en tanto error de comprensión. Por un lado, el caso en que el destinatario

doctrina, especialmente en lo que respecta al error de tipo, pero también en este ámbito respecto del error de prohibición. Puppe, I., "Irrtum und Tatumstände $\$ 16$ ” en Kindhäuser, U., Neumann, U. y Paeffgen, H.U. (coord.), Nomos Kommentar, Nomos, Baden-Baden, 2005, pp. 460 ss.

58 Jakobs (nota 5), p. 668.

${ }^{59}$ Cfr. Pieroth y Schlink (nota 36), pp. 97 ss.

${ }^{60}$ Hufen, F., Staatsrecht II Grundrechte, Verlag C.H. Beck München, Múnich, 2009, pp. 51 ss.

61 Por todos Roxin (nota 8), p. 708, quien menciona que una excepción a la imposibilidad de ponderación de vida versus vida, es el caso del estado de necesidad defensivo, pues no se le puede exigir a alguien que asuma el riesgo de su muerte o lesiones graves con cargo a que otro se salve de ese riesgo de muerte o de lesiones graves. 
de la norma no conoce en absoluto el mandato o prohibición; y el caso del destinatario que conoce el mandato o prohibición, pero no entiende el contenido del mismo y por eso se le exige una "obediencia ciega" a su respecto ${ }^{62}$. Sin embargo, la norma como línea de comportamiento solo puede ser obedecida en tanto el destinatario de ella comprenda el contenido de la misma. En la literatura latinoamericana una de las pocas menciones que se hacen a esta distinción ha sido muy bien planteada por Zaffaroni, quien señala que en el caso de las minorías culturales el estándar no se sitúa en el conocimiento de la norma, sino que un déficit de comprensión de la misma, y él denomina a esto error de comprensión como un subtipo dentro del error de prohibición ${ }^{63}$.

\section{cc) La internalización}

En el caso de la internalización de las normas o más bien de la falta de internalización de las mismas, no se trata ya de un mero caso de falta de comprensión, sino que se encuentra más cercano a un caso extremo de inimputabilidad ${ }^{64}$. El autor tiene un parámetro de significado o de valoración de los bienes que se consideran jurídicamente valiosos, diferenciado y divergente respecto del parámetro dominante de la sociedad. Quien ha crecido en parámetros diferenciados de lo que es bueno o malo, lo correcto e incorrecto, lo justo o lo injusto de manera casi hermética, se encuentra motivado por un orden normativo distinto a quien ha crecido en una comunidad integrada que es la que determina el contenido de las normas vigentes, vinculantes para todos los miembros de la sociedad. El autor que se encuentra en dicha situación para que tenga una internalización deficitaria o inexistente de las normas dominantes tiene que haber actuado de buena fe, no habiéndose siquiera representado en la posibilidad de estar actuando contra Derecho. Él se mueve en el plano de la corrección de su actuar.

Esta internalización deficitaria o inexistente es lo que Jakobs sitúa en el contexto de la socialización exótica (exotische Sozialisation), es más bien una consecuencia de la socialización exótica ${ }^{65}$. La premisa entonces es la siguiente: el autor tiene un sistema de valoración diferenciado, este ha sido determinado por su pertenencia a una identidad cultural particular, distinta de la identidad cultural dominante y, por consiguiente, su motivación es distinta al resto de los integrantes de la sociedad que no son miembros de esa identidad cultural ${ }^{66}$. Él pertenece a un orden de cosas distinto y la impresión que tenga de las normas va a depender del nivel de contacto que tenga este con la sociedad dominante y, por lo tanto, con el ordenamiento jurídico de normas vinculantes. De lo anterior se sigue que la existencia o inexistencia de la internalización va a depender de

${ }^{62}$ Velten, P., Normkenntnis und Normverständnis, Nomos Verlagsgesellschaft, Baden-Baden, 2002, pp. 3 y 10. "blind gehorchen".

63 Alagia, A., Slokar, A. y Zaffaroni, E., Derecho Penal, Ediar, Sociedad Anónima Editora, Comercial, Industrial y Financiera, Buenos Aires, 2003, p. 736.

${ }^{64}$ Jakobs (nota 5), p. 659. Köhler (nota 49), p. 438.

${ }^{65}$ Ibid., Jakobs.

66 Ibid. 
dos factores: por una parte, del mayor o menor contacto efectivo que tenga el destinatario de la norma con el ordenamiento jurídico. A mayor contacto, más difícil será afirmar que hay falta o déficit en la internalización de las normas ${ }^{67}$. Por otra parte, será determinante el nivel de integración que tenga el destinatario de la norma en la cultura dominante (conocimiento del idioma, integración social, nivel de educación o situación laboral, etc. $)^{68}$. Mientras más integrado se encuentre el sujeto, el alegato acerca de la internalización deficiente o inexistente se vuelve más y más implausible ${ }^{69}$.

\section{La antijuridicidad eventual o el comportamiento dudoso respecto de la misma}

La conciencia eventual de la antijuridicidad se refiere a que el autor que ejecuta el hecho se representa en la posibilidad de que ese comportamiento sea contrario a Derecho. Y actúa entonces con conciencia de la antijuridicidad por el solo hecho de representarse en la posibilidad, es decir, de actuar sobre la duda de la corrección de su comportamiento. El fundamento radica en que el autor ha tomado en cuenta la posible dañosidad de su conducta, pero pese a ello decide igualmente llevarla a cabo en vez de renunciar a la realización de su acción. Quien actúa con conciencia eventual de la antijuridicidad -al igual que en materia de dolo eventual- no sabe con certeza que realiza una conducta socialmente nociva, pero lo considera como supuesto posible ${ }^{70}$.

El parámetro de la antijuridicidad eventual tiene como fundamento que el ordenamiento jurídico penal se basa en un respeto por la autonomía de los individuos, así como de las esferas de libertad que tienen los mismos ${ }^{71}$. Así, quien toma el riesgo de una eventual dañosidad social y le resulta indiferente ese resultado dañoso, actúa con indiferencia frente al Derecho en su totalidad y por eso debe aceptar las consecuencias que recaigan sobre ese comportamiento. Se reprocha el tomar el riesgo de realizar una conducta socialmente dañosa. Este parámetro resulta especialmente complejo en el caso de quienes tienen una identidad cultural diferenciada, pues quien actúa como ajeno a la sociedad dominante y, por tanto, ajeno al ordenamiento jurídico, actúa normalmente

${ }^{67}$ Neumann (nota 45), p. 584. Laubenthal, K. y Baier, H., "Durch die Ausländereigenschaft bedingte Verbotsirrtümer und die Perspektiven europäischer Rechtsvereinheitlichung”, en Pötz, P.G., Goltdammer's Archiv für Strafrecht, R.v. Decker, Heidelberg, 2000, p. 209.

${ }^{68}$ El Código Penal peruano reconoce a la socialización exótica como una causal excluyente de la culpabilidad. Art. 15 CP per.: "El que por su cultura o costumbres comete un hecho punible sin poder comprender el carácter delictuoso de su acto o determinarse de acuerdo a esa comprensión, será eximido de responsabilidad. Cuando por igual razón, esa posibilidad se halla disminuida, se atenuará la pena”. Algo similar dispone el Artículo 33 del Código Penal colombiano, pero esta vez respect de la inimputabilidad. „Es imputable quien en el momento de ejecutar la conducta típica y antijurídica no tuviere la capacidad de comprender su ilicitud o de determinarse de acuerdo con esa comprensión, por inmadurez sicológica, trastorno mental, diversidad sociocultural o estados similare".

${ }^{69}$ Ibid., (nota 65).

${ }^{70}$ Puppe, I., "Bemerkungen zum Verbotsirrtum und seiner Vermeidbarkeit", en Rogall, K., Puppe, I., Stein, U., Wolter, J., Festschrift für Hans-Joachim Rudolphi zum 70. Geburtstag, Luchterhand Wolter Kluwer, Múnich, 2004, p. 234.

${ }^{71}$ Köhler (nota 49), p. 409. 
sobre la duda de casi todas sus acciones cotidianas sin siquiera reflexionar respecto de la posibilidad de la dañosidad social de su conducta. Por ejemplo, el extranjero de una cultura oriental que llega a un país occidental en que no conoce el idioma, en que no conoce la legislación, probablemente actúa hasta en sus más mínimos pasos siempre con dudas sobre la corrección de sus actos, pues desde comprar un billete de tranvía hasta fumarse un cigarrillo en la calle implican acciones, en principio inofensivas, pero cuyo procedimiento al no haberse realizado con anterioridad resulta siempre dudoso o a lo menos temeroso.

\section{Vencibilidad}

\section{a. Concepto}

Un error de prohibición es vencible si el autor, de acuerdo con sus facultades individuales y el debido esfuerzo de sus facultades intelectuales y de sus concepciones valorativas, pudo haber reconocido el injusto de su actuar. Es vencible también un error si el autor tuvo un motivo (Anlass) perceptible para reflexionar sobre la conformidad a Derecho de su actuar, de manera tal que se haya podido informar al respecto (Erkundigungspflicht $)^{72}$.

\section{b. Fundamentos}

El examen de la vencibilidad es el eje central en el que se va a determinar si el error de prohibición da lugar a la absolución o bien a una posible atenuación de la pena, de acuerdo con las legislaciones que sigan la teoría de la culpabilidad, hoy prácticamente indiscutida en la doctrina penal ${ }^{73}$. Si el error de prohibición es invencible se excluye la culpa. Si el error de prohibición es vencible, no puede tener lugar un reproche total de la culpabilidad, luego se pregunta en qué medida y bajo qué condiciones tiene lugar este reproche y lo será, en general, mediante una atenuación obligatoria o facultativa de la pena ${ }^{74}$. El examen de vencibilidad tiene un considerable rol a nivel procesal, pues representa especiales dificultades probatorias, ya que en gran medida $-y$ pese a que la doctrina mayoritaria descarta que sea un hecho meramente psicológico- supone probar

\footnotetext{
${ }^{72}$ Neumann (nota 45), p. 593.
}

${ }^{73}$ Kindhäuser (nota 55), pp. 227-230. Neumann (nota 45), pp. 572-610. Roxin (nota 8), pp. 387 ss. Exponente de la teoría del dolo hoy queda aisladamente Schmidhäuser. Schmidhäuser, E., Strafrecht Allgemeiner Teil, Mohr, Tubinga, 1984, capítulo 7.

${ }^{74}$ En Alemania, de acuerdo con el $\$ 17$ StGB, se estableció la atenuación facultativa de la pena. Esta situación no está exenta de discusión, y son varias las voces en la doctrina que levantan la tesis de una atenuación obligatoria de la pena. Por todos, Roxin, C. "Kolloquium über Strafrecht und Kriminologie, Ungelöste Probleme beim Verbotsirrtum”, en: Hans Joachim Hirsch (coord.) Deutsch-spanisches Strafrechtskolloquium 1986: dogmatischer Teil der Strafrechtsreform, Sanktionensystem, Bekämpfung der Wirtschaftskriminalität, Nomos, Baden-Baden, 1987, pp. 81-87. 
estados mentales del sujeto ${ }^{75}$. Por otra parte, la suposición de que quien se integra a una sociedad desconocida siempre tiene la carga de la información, implica abrir la puerta a la afirmación de la culpa en la conducción de la vida (Lebensfübrungsschuld) ${ }^{76}$ y esa afirmación resulta inadmisible a la luz del principio de culpabilidad entendido como culpabilidad de hecho y no culpabilidad de autor.

La imposición de la pena supone necesariamente culpabilidad ${ }^{77}$, y en virtud de que el error invencible excluye la culpabilidad es precisamente en este ámbito donde se tiene que hacer más intensa la ponderación de las valoraciones culturales particulares.

La doctrina mayoritaria opera sobre la siguiente premisa al momento de afirmar culpabilidad y excluir el error de prohibición: si al autor tiene una conciencia actual o potencial de la antijuridicidad, actúa de manera culpable y se excluye, por tanto, la posibilidad de un error de prohibición ${ }^{78}$. Por el contrario, si falta la conciencia de la antijuridicidad se encuentra el sujeto en error de prohibición y dependiendo de si este era vencible o invencible se dará lugar entonces a la exculpación y, por tanto, absolución; o bien a una atenuación, en principio, facultativa de la pena ${ }^{79}$.

Resulta central en el examen de la vencibilidad si es que el autor del hecho contaba con la libertad de poder decidirse en favor del comportamiento conforme a Derecho y contra el comportamiento antijurídico o contrario a él. Solo si el autor actuó con esa libertad y aun así se decidió por un comportamiento injusto, es posible afirmar la responsabilidad penal ${ }^{80}$. No se puede afirmar libertad de la voluntad si el autor no tiene una internalización de las normas adecuada o bien no comprende el sentido de las disposiciones penales. Esto reviste especial importancia en los casos en que el autor pertenece a una identidad cultural distinta de la identidad dominante, que determina el acceso de este a la información jurídica. En este supuesto es la determinación cultural del autor la que le impide considerar en el caso concreto sanciones penales estatales, pues él no tiene la capacidad de reflexión -debido a su determinación cultural diferenciada- respecto del contenido del injusto. Ya sea porque ese acto en su realidad cultural no es un acto socialmente dañino; o bien porque ni siquiera se tematiza como un acto de relevancia que merezca especial reflexión en su contexto cultural.

\section{c. El motivo}

En la doctrina mayoritaria se entiende que existe motivo por parte del autor, siempre que este dude respecto de la conformidad a Derecho de su actuar ${ }^{81}$. Como ya

${ }^{75}$ Un análisis más detenido al respecto en Platzgummer, W., Die Bewußtseinsform des Vorsatzes, Springer, Viena, 1964, pp. 83 ss.

${ }^{76}$ Manso, T., Normunkenntinis aus belastenden Gründen, Nomos, Baden-Baden, 2009, p. 55.

77 Por todos Roxin (nota 8), p. 541.

78 Por todos Neumann (nota 45), p. 578.

${ }^{79}$ Ibid.

${ }^{80}$ Rudolphi (nota 55), p. 14.

${ }^{81}$ Neumann (nota 45), p. 596. 
se mencionara con anterioridad, la conciencia de la contrariedad a la moral, a las costumbres o a la posible dañosidad social de un hecho no sirven por sí solas para afirmar conciencia de la antijuridicidad. Sin embargo, la conciencia de que se contraviene la moral, las costumbres o de que existe una posible dañosidad social, sí sirve para afirmar un motivo ${ }^{82}$. Si se afirma un motivo surge entonces para el autor un deber de informarse (Erkundigungspflicht $)^{83}$. Pero esta precisión del motivo como presupuesto del deber de informarse no deja de estar exenta de críticas, pues si bien se señala que tanto el reconocimiento de la contrariedad a la moral, a las costumbres o bien la dañosidad social no puede por sí solo equivaler a tener conocimiento de la antijuridicidad por ser conceptos imprecisos y variables ${ }^{84}$, sí pueden constituir un motivo. Esto sigue siendo problemático e insatisfactorio, pues se hace alusión a criterios extrapenales, a conceptos indeterminados, pero que igualmente tienen un rol central en materia penal, y esto puede llevar a una aplicación de criterios arbitrarios. Principalmente si uno entiende que la integración de estos conceptos indeterminados se hará desde la esfera del experto (juez) y no desde la esfera del lego. Y aun cuando se hiciera desde la esfera del lego, no desaparece la arbitrariedad si es que se integra atendiendo a criterios de la concepción dominante de la sociedad y no abriéndolos a las identidades culturales coexistentes. Una solución racional sería o bien la objetivación de dichos conceptos -lo que aparece en la práctica como inviable-, o bien la apertura a la ponderación de las concepciones valorativas de la moral, las costumbres y la dañosidad social de cada una de las identidades culturales coexistentes bajo un mismo ordenamiento jurídico. Solo así se salva el peligro de la arbitrariedad.

El criterio es excesivamente amplio, y finalmente todo puede constituir un motivo, por lo mismo es que se puede afirmar que incluso la mínima idea de causar un mal, aunque no sea plausible en sentido jurídico, genera en el autor un motivo y el consiguiente deber de informarse ${ }^{85}$.

\section{Cultural defense y cultural offense}

\section{a. Consideraciones previas}

El tratamiento del error de prohibición se vuelve mucho más complejo cuando se trata de países de tradición anglosajona. La complejidad radica en que a) no detentan la misma estructura del delito que los países de tradición continental, sin embargo, utilizan igualmente las mismas figuras en la doctrina y muchas veces en la jurisprudencia ${ }^{86}$.

\footnotetext{
82 Ibid.

83 Ibid. p. 599.

${ }^{84}$ Ibid. pp. 578-579.

85 Kaufmann (nota 34), p. 144.
}

${ }^{86}$ Ante la creciente crítica por la evidente contradicción en esta materia, es necesario mencionar la réplica que hace Fletcher al respecto al señalar con relación a la incorporación de la nomenclatura alemana en el análisis jurídico: "este sistema no es una doctrina alemana, más de lo que la teoría de la relatividad 
b) se vuelve complejo un análisis si se considera que en estos países rige de manera -en principio- absoluta el principio error iuris non excusat. Esto es, no reconocen al error de prohibición como defensa plausible.

Lo que ha ocurrido en estas legislaciones, sin embargo, especialmente en el caso de los Estados Unidos, es que dicha prohibición, prima facie absoluta del error como defensa plausible, se ha ido flexibilizando con la creación de excepciones particulares. En especial por una exigencia intensificada específica de mens rea en los delitos. Lo que se exige es specific criminal intent ${ }^{87}$. La razón que se ha esgrimido es que con esto se quiere evitar llegar a resultados manifiestamente injustos en las sentencias ${ }^{88}$. Ahora bien, el error de prohibición aislado en la exigencia intensificada de mens rea en el delito particular generalmente no se plantea como argumento único, sino que se presenta en conjunto con otras defensas plausibles, usualmente en relación complementaria con la argumentación de inimputabilidad (insanity) o con un alegato de error de tipo (mistake of fact). Esto no es más que un juego interpretativo tanto de la doctrina como de la jurisprudencia para admitir el error de prohibición, pero para seguir siendo fieles a su sistema y sostener que "el error de prohibición no constituye defensa plausible"...salvo en ciertos casos, y esos casos serán tantos como el juez determine que sean, pues la exigencia de specific criminal intent es una exigencia más bien discrecional en donde las habilidades interpretativas del juez van a determinar su procedencia o improcedencia. El resto del trabajo lo hace la sujeción al precedente.

Ahora bien, el reconocimiento del error de prohibición como defensa plausible se ve reafirmado por una estrategia de defensa mucho más de avanzada en los casos que revisten alguna particularidad cultural, esta es la llamada cultural denfense (defensas culturales). Desde hace ya tiempo en Estados Unidos se viene sosteniendo la defensa cultural para los casos cuya ocurrencia se haya determinado por las valoraciones culturales diferenciadas del autor. En el plano europeo-continental se enfoca el análisis desde el punto de vista de las bien llamadas cultural offences, mientras que el análisis en países de tradición jurídica anglosajona se concentra en las llamadas cultural defenses ${ }^{89}$. El problema subyacente es idéntico: la interacción de las valoraciones culturales particulares con la normativa vigente $y$, en especial, con el error de prohibición. Lo que difiere es el enfoque con que se realiza el análisis. En este sentido, mientras la cultural offense parte su análisis desde el examen del hecho que se considera como delictivo; la cultural defense se enfoca desde

de Einstein representa a la teoría científica de la física alemana (o suiza o americana)". (...) "this system is not a German doctrine, any more than Einstein's theory of relativity represents a German (or Swiss or American) science of physics". Fletcher, G.P., The Grammar of Criminal Law, Oxford University Press, Oxford, 2007, pp. 54-55.

${ }^{87}$ Keedy, E., "Ignorance and Mistake of Law”, Harvard Law Review, Vol. 22, (Dec., 1908), p. 89.

${ }^{88}$ Vogeley, S., "The mistake of law defense in International Criminal Law", en Yee, S. (coord.) International crime and punishment, University Press of America, Lanham, Inc. Oxford, 2003, p. 97.

${ }^{89}$ Van Broeck, J., Cultural Defence and Culturally Motivated Crimes (Cultural offenses), European Journal of Crime, Criminal Law and Criminal Justice, Vol. 9/1, 2001, pp. 1-32. 
la perspectiva del autor. A continuación se precisarán los límites -o la falta de ellos- y la relación que existe entre estos dos conceptos.

\section{b. Determinación y delimitación}

La línea divisoria entre cultural offence y a cultural defense no es del todo clara, pues ambas se encuentran en un nivel complementario de aplicación. En general tendrá lugar una cultural offence, y consecuentemente lo hará una cultural defense, pero esto no siempre es así. Es preciso destacar que la existencia de una cultural offence será determinada por el hecho delictivo, y por la motivación del autor. Es decir, si el hecho y la motivación obedecen a una razón cultural. Ejemplo de ello es el caso de la circuncisión. Este hecho tiene un trasfondo cultural que obedece a la práctica de un ritual religioso y, por tanto, se puede afirmar a su respecto que es una cultural offence. La ofensa cultural o cultural offence se concentra en el hecho cometido por el sujeto, y es central que este hecho revista un carácter cultural indiscutible. Esto ocurre cuando un determinado hecho es visto por esa minoría cultural como aceptado, tolerado o motivado ${ }^{90}$, pero que en la realidad de la identidad cultural dominante aparece como constitutivo de delito ${ }^{91}$. Cultural defense, sin embargo, se precisa y determina por medio de la creencia del autor ${ }^{92}$. Es decir, cómo los caracteres culturales del sujeto son los que determinan la comisión del hecho delictivo, ya sea porque detenta una valoración particular de un determinado bien jurídico, o bien porque en razón de una firme determinación cultural en su desarrollo tiene una concepción diversa de lo bueno, lo malo, lo permitido o lo prohibido. Para determinar la influencia de la historia cultural del autor en su comportamiento es necesario que el sujeto tenga una identidad cultural determinada. No basta entonces con que un sujeto aislado se sienta "culturalmente especial". Es preciso que haya una cierta pertenencia de grupo, una identidad cultural que lo sustente ${ }^{93}$.

La defensa cultural o cultural defense puede ser entendida en sentido sustantivo como una figura que permite la disminución de la pena o bien la absolución del sujeto, siempre que el hecho considerado como delictivo fuera realizado por el autor de buena fe (good faith). Una buena fe que se sustenta en las creencias enraizadas en su tradición cultural, y que hacen que el sujeto ni siquiera se represente en la posibilidad de que su actuar sea antijurídico ${ }^{94}$. Por otro lado, la defensa cultural puede ser considerada desde un aspecto adjetivo, entendido como los medios otorgados en juicio que facilitan

${ }^{90}$ Ibíd., p.5. "A cultural offence is an act by a member of a minority culture, which is considered an offence by the legal system of the dominant culture. That same act is nevertheless, within the cultural group of the offender, condoned, accepted as normal behavior and approved or even endorsed and promoted in the given situation".

${ }^{91}$ Ibid. La cultura mayoritaria, es la cultura que define los pilares del Derecho vigente.

92 Ibid., p. 5.

${ }^{93}$ Hörnle (nota 7 "Strafrechtliche..."), p. 317.

${ }^{94}$ Lyman, J.C., Cultural defense: Viable Doctrine, or Wishful Thinking?, 9 Criminal Justice Journal 87, 1986, p. 98. "A cultural defense will negate or mitigate criminal responsibility where acts are committed under a reasonable, good-faith belief in their property, based upon the actor's cultural heritage or tradition". 
la defensa del imputado en atención a que este detenta una identidad cultural distinta de la mayoría. En el Derecho procesal chileno esto se representa en la figura de los facilitadores interculturales ${ }^{95}$, quienes tienen la tarea de facilitar-como su nombre lo indica- la interacción entre los imputados que pertenezcan a una minoría étnica y los demás intervinientes en juicio, especialmente el juez. Es un "puente intercultural” que más que interpretar a partir de la literalidad, lo que hace es presentar una cosmovisión del imputado 96 .

En su primera acepción, la defensa cultural es también una estrategia de defensa, pues no funciona de manera autónoma como argumento suficiente para determinar la absolución o disminución de la pena, sino que siempre debe ejercerse en relación con otras figuras del Derecho, ya sea la inimputabilidad del imputado, la legítima defensa, el estado de necesidad, o el error de prohibición, entre otras. La defensa cultural se encuentra en relación de complemento con estas figuras, pero hasta ahora no se ha visto que pueda operar como mecanismo autónomo. Lo determinante es que las valoraciones culturales del imputado hayan tenido un rol decisivo en la ejecución del hecho.

Ya sea con la defensa cultural o de la ofensa cultural por separado o en relación complementaria -como ocurre la mayoría de las veces- resulta crucial que las valoraciones culturales del individuo en el caso concreto sean presentadas en juicio y ponderadas por el órgano adjudicador. Lamentablemente, en la mayoría de los ordenamientos jurídicos, salvo que haya norma expresa que se refiera al error culturalmente condicionado ${ }^{97}$, no existe una regla específica que obligue al juez a ponderar una defensa cultural. Sin embargo, se puede sostener que el juez tiene la obligación, en razón del principio de igualdad como igualdad relativa, de ponderar dichos factores. Solo así cumplirá ese juez con una sujeción adecuada al principio de culpabilidad en la determinación de la decisión de condena o absolución. El juez debe buscar criterios interpretativos que permitan integrar en su decisión final las características culturales del hecho objeto de juicio, solo así su sentencia estará justificada interna y externamente ${ }^{98}$.

\section{CONCLUSIÓN}

La ponderación de las valoraciones culturales diferenciadas es una cuestión que merece revisión no solo en el contexto del error de prohibición sino que también bajo el prisma de otras figuras del Derecho, especialmente de la Parte Especial (crímenes de honor, rapto, mutilaciones, etc.). Este trabajo no tiene como pretensión concluir que en todos los casos en que concurra un agente que revista una identidad cultural diferenciada y que tenga una cosmovisión particular respecto de las valoraciones jurídicas de la

95 Defensoría Penal Pública, Modelo de Defensa Especializada para Imputados Indígenas, pp. 164 ss., disponible en www.dpp. cl.

${ }^{96}$ CEJA-JSCA, Informe Reforma Procesal Penal y Pueblos Indígenas, 2006, disponible en www.cejamericas.org.

97 Ver nota 69.

98 Wróblewsky, J., The Juditial Aplication of Law, Kluwer, Holanda, 1992, pp. 61 ss. 
mayoría, deba por necesidad ponderarse positivamente la concurrencia de una valoración cultural divergente que pueda conducir a una atenuación (error de prohibición vencible) o exculpación (error de prohibición invencible). Lo que se concluye del análisis y de los argumentos aquí expuestos es que la ponderación de las valoraciones culturales diferenciadas vincula al juez y, por tanto, la obligación del juez se puede sintetizar en las siguientes premisas: a) el juez debe siempre ponderar las valoraciones culturales diferenciadas; b) esas valoraciones culturales pueden ser ponderadas negativa o positivamente, es decir, puede que sean desechadas por el órgano adjudicador por considerarlas impertinentes y no decisivas en el caso concreto, pero siempre debe justificar esa decisión; c) la evaluación de la cosmovisión particular implica un respeto a la igualdad en términos de igualdad relativa y la sujeción a su consideración es coherencia pura con el existente estado democrático plural de Derecho, por lo mismo no es necesario que exista norma expresa que obligue a dicha ponderación.

La problemática de las valoraciones culturales diferenciadas en materia de error de prohibición se suma a las dificultades frente a la ficción del conocimiento de las normas por parte de los destinatarios de las mismas como criterio suficiente de exigibilidad. Si bien es cierto que esta ficción no debe tener aplicación en materia penal -por considerar que con ello se vulnera el principio de culpabilidad-, el baremo del conocimiento es igualmente utilizado a nivel dogmático en la teoría del error de manera -a lo menosconfusa para el establecimiento de la conciencia de la antijuridicidad. Es necesario realizar una depuración conceptual y establecer una nomenclatura gradual para poder afirmar en consciencia de la antijuridicidad, y en este entendido se opera relativo la premisa de que conocimiento y comprensión, por una parte, no son términos intercambiables y revisten un significado diferenciado en cuanto a su intensidad y exigibilidad. La internalización, por su parte, obedece a la idea de una concepción valorativa divergente. Es un grado más de intensidad, pero no responde a la concepción del desafío al ordenamiento jurídico. El caso de quien desafía es el supuesto en que el destinatario de la norma conoce, comprende e internaliza, pero no está de acuerdo con la cosmovisión que se impone. El caso de quien no internaliza se trata del destinatario que conoce y comprende pero no identifica los patrones de valoración subyacentes a las normas jurídicas como valiosos, pues tiene patrones de comportamiento divergentes. En este contexto es que resulta pertinente atender a la teoría de Hörnle sobre la idea de que es más adecuada la comprensión de las normas penales como mecanismos de protección de valoraciones culturales que de bienes jurídicos propiamente tales ${ }^{99}$.

El baremo para afirmar conciencia de la antijuridicidad debe situarse en a lo menos comprensión. Quien no entiende la norma no actúa con libertad de la voluntad y tiene un déficit de culpabilidad. Este es el primer paso para la constatación del error, seguido de un análisis exhaustivo en el examen de vencibilidad que debe renunciar a las afirmaciones hipotéticas de la conciencia de la antijuridicidad. El asentamiento de la teoría de la culpabilidad en la doctrina mayoritaria ha implicado una renuncia a la exigencia de la

${ }^{99}$ Hörnle (nota 7 "Strafrechtliche..."), p. 321. 
actualidad de la conciencia de la antijuridicidad, satisfaciendo el requisito con la mera eventualidad y con la constatación de cursos mentales del autor. Cuestión que también debiera quedar proscrita a la luz de una sujeción estricta al principio de culpabilidad: nadie puede ser sancionado por sus actuaciones hipotéticas. Afirmar lo contrario podría abrir la puerta a la culpa por la conducción de vida en materia penal y eso no es más que Derecho penal de autor y no de actos.

Es preciso hacer una breve referencia a la responsabilidad estatal que recae en materia de socialización de las normas penales como contrapartida al error de prohibición. En este contexto se presentan dos problemas: la falta de acceso a las normas por parte del ciudadano medio, del lego y con mayor razón de quien proviene de una realidad cultural ajena; y por otra parte, el problema de las realidades interpretativas divergentes de legos y expertos. El Estado sí tiene un deber de socialización de las normas y ese deber no se agota en la ficción del conocimiento, sino que requiere de una socialización efectiva y tangible de las mismas ${ }^{100}$.

Por último y ante las objeciones del debilitamiento de la norma en caso de abrir paso a las defensas culturales, cabe decir que si bien dichas objeciones son por cierto atendibles, el fundamento de la problemática en materia de ponderación de las valoraciones culturales diferenciadas es un problema de culpabilidad, y sostener que la reafirmación de los criterios preventivos tiene más peso específico que una sujeción estricta al principio de culpabilidad, es entender que el Derecho penal no es más que puro utilitarismo y que la labor ejemplificadora justificaría la imposición de una pena, y ello no solo es incorrecto de acuerdo con las teorías modernas de la pena sino que es además inhumano ${ }^{101}$.

\section{BIBLIOGRAFÍA}

Alagia, A., Slokar, A. y Zaffaroni, E., Derecho Penal, Ediar, Sociedad Anónima Editora, Comercial, Industrial y Financiera, Buenos Aires, 2003, p. 736.

Baumann, J., Weber, U. y Mitsch, W., Strafrecht Allgemeiner Teil, Gieseking, Bielefeld, 2003.

BInding, K., Die Normen und ibre Übertretung I, Verlag von Felix Meiner, Leipzig, 1916.

BINDING, K., Die Normen und ibre Übertretung III, Wilhelm Engelman, Leipzig, 1918.

Bollacher, M, Der junge Goethe und Spinoza. Studien zur Geschichte des Spinozismus in der Epoche des Sturms und Drangs, Max Niemeyer Verlag, Tubinga, 1969.

Brockhaus Enzyklopädie, "Volumen 16, Kultur, Brockhaus, Wiesbaden, 17ª Ed., 1976, p. 61. CEJA-JSCA, Informe Reforma Procesal Penal y Pueblos Indígenas, 2006, disponible en www.cejamericas.org.

Córdoba Roda, J., El conocimiento de la antijuridicidad en la teoría del delito, Bosch, Barcelona, 1962.

${ }^{100}$ Al respecto resulta ilustrativo el ejemplo de las leyes de Calígula: "It would be like sanctioning the practice of Caligula who, published the law "but it was written in a very small handwriting, and posted up in a corner, so that no one could make a copy of it". Screws v.United States (1957), Supreme Court of the United States, 325 U.S. 225.

${ }^{101}$ Hörnle, T. Straftheorien, Mohr Siebeck, Tubinga, 2011, p. 51 ss. 
Defensoría Penal Pública, Modelo de Defensa Especializada para Imputados Indígenas, pp. 164 ss., disponible en www.dpp. cl.

Fikentscher, W, Law and Anthropology, Verlag der Bayerischen Akademie der Wissenschaften, Múnich, $1^{\text {a }}$ Ed., 2009.

Fletcher, G.P., The Grammar of Criminal Law, Oxford University Press, Oxford, 2007.

Groteguth, T., Norm- und Verbots- (Un-) kenntnis, Duncker und Humblot, Berlin, 1993.

Habermas, J., Vorstudien und Ergänzungen zur Theorie des kommunikativen Handelns, Suhrkamp, Fráncfort, $1^{\mathrm{a}}$ Ed., 1995.

HöRnle, T., Grob anstößiges Verbalten, Klostermann, Fráncfort, 2005.

HÖRNLE, T., "Strafrechtliche Verbotsnormen zum Schutz von kulturellen Identitäten", en Dreier, H. y Hilgendorf, E., (coord.), Kulturelle Identität als Grund und Grenze des Rechts, Nomos, Stuttgart, 2008, pp. 315-339.

HöRnle, T., Straftheorien, Mohr Siebeck, Tubinga, 2011.

Hufen, F., Staatsrecht II Grundrechte, Verlag C.H. Beck München, Múnich, 2ª Ed., 2009.

Jakobs, G., Derecho Penal Parte General, 2a Ed., Marcial Pons, Madrid, 1997.

Jescheck, H.H. Lebrbuch des Strafrechts, Duncker \&Humblot, Berlin, 4ª Ed. 1996.

Kant, I., Werkausgabe, Bd. IX: Schriften zur Naturphilosophie, Wissenschaftliche Buchgesellschaft, Fráncfort, 1983.

Kaufmann, A., Das Unrechtsbewußtsein, Scientia Verlag Aalen, Darmstadt, 1985.

KeEdy, E., "Ignorance and Mistake of Law", Harvard Law Review, Vol. 22, (Dec., 1908), pp. 75-96.

KIM, N., "The Cultural defense and the problem of cultural preemtion: a framework for analysis", New Mexico Law Review 27: 101-139.

Kindhäuser, U., Strafrecht Allgemeiner Teil, Nomos, Baden-Baden, $5^{\text {a Ed., }} 2011$.

KöHLER, M., Strafrecht Allgemeiner Teil, Springer, Berlin, 1997.

Laubenthal, K. y Baier, H., "Durch die Ausländereigenschaft bedingte Verbotsirrtümer und die Perspektiven europäischer Rechtsvereinheitlichung”, en Pötz, P.G., Goltdammer's Archiv für Strafrecht, R.v. Decker, Heidelberg, 2000, p. 209.

Lyman, J.C., Cultural defense: Viable Doctrine, or Wishful Thinking?, 9 Criminal Justice Journal 87, 1986, pp. 87-117.

Manso, T., Normunkenntinis aus belastenden Gründen, Nomos, Baden-Baden, 2009.

Maurach, R. y Zipf, H., Strafrechts Allgemeiner Teil, C.F. Müller Juristischer Verlag, Heidelberg, $7^{\text {a }}$ Ed., 1985.

MAYER, M.E., Rechtsnormen und Kulturnormen, Wissenschaftliche Buchgesellschaft, Darmstadt, 1965.

MöLlers, C. "Pluralität der Kulturen als Herausforderung an das Verfassungsrecht?", en Dreier, H. y Hilgendorf, E., (coord.), Kulturelle Identität als Grund und Grenze des Rechts, Nomos, Stuttgart, 2008, pp. 223-244.

Neumann, U., “\$17 Verbotsirrtum”, en Kindhäuser, U., Neumann, U. y Paeffgen, H.U. (coord.), Nomos Kommentar, Nomos, Baden-Baden, 2005, pp. 572-610.

Perpeet, W., "Kultur, Kulturphilosophie" en Ritter, J. y Gründer, K. (coord.) Historisches Wörterbuch der Philosophie, Volumen 4, Wissenschaftliche Buchgesellschaft, Darmstadt, 1976, pp. 1309-1324.

Pieroth, B. y Schlink, B., Grundrechte Staatsrecht II, C.F. Müller, Hamburg, $27^{\text {a }}$ Ed. 2011.

Pufendorf, S., De jure naturae et gentium, Sumptibus Friderici Knochii, Fráncfort, 1694.

Puppe, I., "Bemerkungen zum Verbotsirrtum und seiner Vermeidbarkeit", en Rogall, K., Puppe, I., Stein, U., Wolter, J., Festschrift für Hans-Joachim Rudolphi zum 70. Geburtstag, Luchterhand Wolter Kluwer, Múnich, 2004, pp. 231-242.

Puppe, I., "Irrtum und Tatumstände §16" en Kindhäuser, U., Neumann, U. y Paeffgen, H.U. (coord.), Nomos Kommentar, Nomos, Baden-Baden, 2005, 2ª Ed., pp. 460-572. 
Roxin, C. "Kolloquium über Strafrecht und Kriminologie, Ungelöste Probleme beim Verbotsirrtum", en: Hans Joachim Hirsch (coord.) Deutsch-spanisches Strafrechtskolloquium 1986: dogmatischer Teil der Strafrechtsreform, Sanktionensystem, Bekämpfung der Wirtschaftskriminalität, Nomos, Baden-Baden, 1987, pp. 81-87.

Roxin, C., Allgemeiner Teil, C.H. Beck, Múnich, $4^{\mathrm{a}}$ Ed., 2006.

Rudolphi, H.J., Unrechtsbewußtsein, Verbotsirrtum und Vermeidbarkeit des Verbotsirrtums, Verlag Otto Schwarz \& Co., Göttingen, 1969.

SAWILLA, J., Lubmanns Kulturbegriff unter besonderer Berücksichtigung der Gedächtnisproblematik, Grin Verlag, Norderstedt, 2011.

Schünemann, B., Nulla poena sine lege?, de Gruyter, Berlin, 1978.

Schmidhäuser, E., Strafrecht Allgemeiner Teil, Mohr, Tubinga, 1984.

SCREWS v.United States (1957), Supreme Court of the United States, 325 U.S. 225.

Torres, E., "Identidad, creencias y orden penal: la eximente cultural”, en López, A. y Aguado, C (coord.), La protección de bienes jurídicos globales, Anuario de la Facultad de Derecho de la Universidad Autónoma de Madrid, N 17, 2013, pp. 399-450.

VAlerius, B., Kultur und Strafrecht, Duncker \& Humblot, Berlin, 2011.

VAN Broeck, J., Cultural Defence and Culturally Motivated Crimes (Cultural offenses), European Journal of Crime, Criminal Law and Criminal Justice, Vol. 9/1, 2001, pp. 1-32.

Velten, P., Normkenntnis und Normverständnis, Nomos Verlagsgesellschaft, Baden-Baden, 2002.

Vogeley, S., "The mistake of law defense in International Criminal Law", en Yee, S. (coord.) International crime and punishment, University Press of America, Lanham, Inc. Oxford, 2003, pp. 59-99.

Wróblewsky, J., The Juditial Aplication of Law, Kluwer, Holanda, 1992.

ZimmermanN, R., "Römisches Recht und europäische Kultur", en Dreier, H y Hilgendorf, E. (coord.), Kulturelle Identität als Grund und Grenze des Rechts, Nomos, Stuttgart, pp. 29-54. 
